O RETORNO DE LINO NOVÁS

A SÚA TERRA DE ORIXE

\title{
Bernardo Penabade
}

IES Perdouro (Burela) 



\section{CONSIDERACIÓNS PREVIAS}

Antes de entrar de cheo na exposición dedicada ao retorno de Lino Novás á súa terra de orixe, quixera manifestar publicamente o agradecemento a cinco persoas moi especiais que nos honraron coa súa presenza nas Xornadas. En primeiro lugar, á académica Rosario Álvarez, a miña querida profesora, a quen tanto debo e a quen espero non defraudar; ao profesor Andrés Santalla, en representación do equipo humano que se ocupou da produción e realización da versión audiovisual de «Un encuentro singular» e da exposición dedicada ao escritor pola Fundación Ortegalia hai agora dez anos; a Marta Escourido Vieites, tradutora da obra de Himilce Novas; a Vicente Peña Saavedra, polo seu empeño constante e dilatado no tempo en favor da divulgación entre nós da obra de Lino; e á profesora Josefa Paradela Trigo, historiadora, auténtica salvagarda da memoria da súa nai -Amelia Trigo-, protagonista da crónica intitulada $A$ miña viaxe ás Grañas do Sor, de Uxío Carré Alvarellos. Precisamente a ese lugar, ás Grañas do Sor, dispoñémonos a viaxar agora.

\section{PUNTO DE PARTIDA}

Síntome profundamente identificado coa figura de Lino Novás Calvo. Porque as nosas casas nativas están moi próximas - desde unha vese ben a outra- e porque, aínda distanciados temporalmente -algo máis de medio século-, compartimos moitas vivencias. Leo hoxe o que el escribiu e vexo o meu propio retrato da infancia, e non só polo lugar de ambientación. Miña mai fálame moitas veces da súa -«costureira que tivo un fillo que seique era moi listo»-; no lugar de Pesegueiro teño traballado como xornaleiro nos últimos anos da infancia; teño alindado vacas na mesma zona da serra, que seguía sendo igual de perigosa e, por tanto, tiñamos que afrontar a mesma responsabilidade con tan pouca idade; e comparto con el unha formación tardía. No meu caso, nunca tiven un libro de lectura antes dos 15 anos (e aínda encima o primeiro foi a novela de contido etnográfico titulada Gran Sol-de Ignacio Aldecoa-, cun tema totalmente afastado do meu universo, de xeito que entendín moi pouquiño) e non lin ningún de xeito autónomo antes dos 17, cando conseguín o que para min foi un logro persoal a través de El Jarama, de Rafael Sánchez Ferlosio. 
Leo hoxe a obra do noso Lino desde unha tripla perspectiva: a do docente que le para si, mais especialmente para outros; a do docente moi implicado nos reforzos educativos a fillos e fillas de inmigrantes -algúns que con 15 anos traballan entre as 5 da madrugada e as 8 da mañá, e que despois aínda teñen forza para iren á escola e abriren os libros-; e, sobre todo, leo hoxe a obra do noso Lino desde As Grañas do Sor, vendo Pesegueiro, falando cos Novases e cos Calvos, e admirando a visión do mundo que nos deixou escrita alguén que foi de alí: un dos nosos que marchou polo mundo coa mente aberta para que o mundo entrase nel. Precisamente estimulado por esa admiración, neste feliz momento en que o ritmo da historia propiciou o reencontro coa nosa terra do fillo que a deixou hai un século, considero que pode ser útil facer memoria de como coñecemos o seu nome e como pouco a pouco fomos entrando na súa obra. Facémolo co desexo de abrir portas a outros posibles lectores, moi especialmente deste lado do Atlántico. Oxalá o consigamos.

\section{POR TODOS OS CAMIÑOS... SE PODE CHEGAR}

Lino-Novás-Calvo: así, co nome e os dous apelidos, todo dun tirón, foi como o vin escrito por primeira vez e como se me foi gravando na memoria. Sendo eu un neno de nove anos, no mes de agosto de 1973, encontrei unha novidade rechamante no programa das festas patronais das Grañas do Sor. Ademais do anuncio das sesións de «fogos de artificio», da «misa solemne» e da sesión vermú e posterior verbena cunha "famosa orquestra», por vez primeira o cartel do San Mamede incluía un anuncio especial: o da disputa dun trofeo de fútbol. Para un neno que comezaba a ler coa autonomía que se pode ter a esa idade, a novidade transmitía unha inmensa dose de orgullo. O Gransor, o equipo que nos representaba, estaba formado polos mozos nacidos no decenio de 1950 e aqueles "homes», con dez anos máis, eran os nosos modelos que seguir.

Nós xa sabiamos do Teresa Herrera na Coruña e do Concepción Arenal en Ferrol; e, desde ese momento, entrabamos no mundo co Trofeo Novás Calvo.

Como mínimo nunha das ocasións en que o Gransor gañou o torneo, a entrega formal da copa realizouse en plena verbena. A orquestra fixo un descanso e os «heroes» locais subiron ao palco para recolleren a copa dedicada a Lino Novás 
Calvo entre os vítores populares. $\mathrm{O}$ ambiente foi tan intenso que aínda permanece gravado entre os meus recordos.

Neste contexto de relación do nome de Lino Novás Calvo con vivencias tan intensamente positivas, enténdese o interese por coñecer a súa biografía de home ilustre. A base informativa eran os comentarios escoitados a persoas adultas, moi especialmente a Jesús Pardo Novás, Cefucho, fillo dunha medio irmá do escritor e impulsor do torneo deportivo. Mais o 23 de xaneiro de 1976, La Voz de Ortigueira publicaba un extenso artigo doutro axente cultural infatigábel, Antonio Rivera Losada, o que fora secretario persoal de Camilo José Cela, que reivindicaba o recoñecemento para Lino Novás, a quen tratara persoalmente a través da revista Papeles de Son Armadans. Este texto escrito sempre o tivemos como referencia.

Desde hai 45 anos, nin Cefucho nin Antonio Rivera perderon ningunha ocasión para alentar a presenza de noticias sobre o escritor nas páxinas dos xornais. Fixérono co fútbol, fixérono con motivo da súa xubilación como profesor universitario (1974), no momento do falecemento (1983), e fixérono tamén cando ían aparecendo as diferentes teses de doutoramento e os libros correspondentes. Foi así como coñecemos os nomes de Raymon Souza, Lorraine Elena Roses, Cira Romero e Carlos Espinosa, entre outros.

Aquela divulgación intelixente conseguía simultaneamente dous obxectivos: a) honrar a figura do parente, do escritor con orixe local; e b) dar a coñecer a parroquia das Grañas e prestixiala mostrándoa como berce de personalidades moi destacadas por unha ou outra razóns (Lino Novás, Mamede Casanova, Teolindo Soto Barro, Luís de Funes...).

Andando o tempo, xa con case 18 anos, na libraría e imprenta de D. David Fojo, outro valedor de Novás en Ortigueira, encontrei o Pedro Blanco. El Negrero de Lino Novás, na edición de Espasa-Calpe. Nada máis facerme con el, cheguei á casa e púxenme a ler coa ilusión de que me gustase moito e que chegase a comprender ben o libro do "escritor das Grañas». A ilusión transformouse en desilusión. Co título de bacharel debaixo do brazo, xa me sentía lector autónomo e nada máis lonxe da realidade: comecei a lectura e naufraguei rapidamente.

Esa experiencia aletargou a Lino Novás dentro de min. As causas foron ben concretas: o fracaso lector, o final do torneo futbolístico, o deixar de seguir as páxinas do xornal local e a irresponsabilidade do estudante universitario que non 
soubo pedirlle axuda nesta materia a profesores como Darío Villanueva ou Luís Martul Tobío, que estarían encantados de orientarme.

Tendo xa a licenciatura e exercendo a docencia, caeume nas mans un completísimo catálogo dunha libraría e editorial de Sevilla. Boteille un ollo e dei cun título que me chamou a atención: Maneras de contar. O espírito de amor á terra orixinaria bateume de novo intensamente no peito e sen dilacións fixen o pedido contra reembolso. Cando chegou o exemplar, recibino con entusiasmo e púxenme a ler con toda aquela forza da novidade. Todo comezou realmente moi ben. En cada relato fun descubrindo as características da literatura hispanoamericana que estudara na especialidade de Filoloxía Hispánica. Tanto os contidos temáticos como as ambientacións e mesmo o estilo recordábanme as lecturas de Carpentier, de Horacio Quiroga ou de García Márquez. Gustoume moitísimo o primeiro dos relatos («Peor que un infierno», variación de "Angusola y los cuchillos»), un pouco menos o segundo (a historia da famosa noite de Ramón Yendía, que me recordaba o estilo do Pedro Blanco), mais entusiasmoume o terceiro ( $\mathrm{A}$ ese lugar de donde me llaman»). Unha vez que lin este relato intenso, tenro e próximo, sentinme mal por non reunir antes o conxunto da produción literaria de Lino Novás e por descoñecer aquel libro que se publicara en 1970, uns vinte anos atrás.

\section{DA SORPRESA DECEPCIONANTE Á PAIXÓN POLA SÚA OBRA}

As sensacións mudaron totalmente ao chegar ao relato titulado «Un encuentro singular». Por vez primeira encontraba unha historia ambientada nas Grañas do Sor, o lugar de nacemento común a escritor e lector. A priori esta particularidade tería que ser fonte de orgullo e entusiasmo, mais non foi así. Todo o contrario.

O argumento é moi familiar: un home retorna de Cuba para visitar a súa nai na aldea nativa. Percíbese o Campo das Grañas, coa igrexa e o cruceiro do adro; o cemiterio e o grupo de casas con taberna (entre elas a de Cefucho); a subida á Faladoira e a baixada a Ortigueira, con parada na taberna do Coto, en Devesos. Mais todos estes lugares, como tamén a xente que os poboa, son vistos polos ollos dun renegado que só ve o negativo en todo o que o rodea. Aínda que verbalice un hipotético amor proteccionista pola nai, rexeita a proxenitora. Acaba escapando como o faría un fuxitivo do inferno. 
Neste noso contexto tan actual, en que habitualmente escoitamos manifestacións de autoodio, de papanatismo en favor do alleo e persistente negación do propio, encontrar este relato supuxo unha desmotivación para ler o resto do libro. $\mathrm{O}$ que estaba lendo asocieino con aqueles sonetos tan humillantes que circulaban durante o chamado Século de Ouro:

$$
\begin{aligned}
& \text { Reyno infeliz, país desventurado, } \\
& \text { de España muladar, rincón del mundo, } \\
& \text { áspero, rudo clima, temple ayrado, } \\
& \text { infiel, bárbaro trato, sitio inmundo, } \\
& \text { gente sin sociedad, campo infecundo. } \\
& \text { En el nombre de Dios Santo y Eterno, } \\
& \text { con quanta fuerza tiene el exorcismo, } \\
& \text { te conjuro y apremio, triste Averno, } \\
& \text { para que me declares por ti mismo, } \\
& \text { si eres en realidad el propio Infierno, } \\
& \text { o si eres retrato del abismo. }
\end{aligned}
$$

Os prexuízos son ben coñecidos, tanto contra a terra como contra a súa xente. A terra está mal situada: somos «rincón do mundo». Temos un clima acorde co lugar que ocupamos (rudo, áspero) e poboamos unha terra tan infecunda que só dá toxos e xestas. En consonancia co ambiente en que nos criamos, carecemos de educación (somos de bárbaro trato, porque non nos relacionamos... enténdese que con xente de «educación esmerada»). É por iso que nacemos para ser subordinados, temos que ser escravos fieis dos que naceron para ser amos. O texto xa o di claramente: a nosa terra é un inferno e, por dedución, os seus habitantes somos encarnacións do demo.

Así e todo, o relato de Lino aínda se me pareceu máis a aquel outro que nos mostra como cochos, egoístas, primitivos e famentos:

[...] suelo nunca barrido ni regado:

campo de abrojos, todo matizado, berzas gigantes, pulgas filisteos, nabos de El Cayro, búcaros pigmeos, 
trage tosco y estilo mal limado;

montes que llegan a la ardiente esfera,

papas de millo en concas de madera,

natas acedas, buches de pescados,

pan de Guinea, techos ahumados,

candelas de resina con tericia,

este es, hermano, el Reyno de Galicia.

Naquel momento, equivocadamente, pensei que estaba lendo «máis do mesmo", do que tan fartos estamos. Aínda así e todo, o destino quixo que aparecesen novas oportunidades de reenganchar co patrimonio cultural de Lino Novás Calvo.

Pouco despois desta decepción, outro feliz acaso chamounos de novo a profundar na obra do veciño emigrado. O escritor Xosé Luís Méndez Ferrín facilitounos unha fotocopia do texto intitulado «La primera lección» e suxeriunos que nos ocupásemos de facer unha versión galega.

As primeiras liñas de «La primera lección» inmediatamente nos levaron a «Un encuentro singular» e á biografía do autor, malia que neste caso a historia sexa ambientada nun momento anterior. Aínda que non se cita unha data específica, a coincidencia do contido coas circunstancias persoais polas que pasou o autor na infancia permítenos situar o tempo histórico por volta de 1910.

O protagonista é un neno de sete anos que deixa a súa terra para emigrar a Cuba. Con tal motivo, parentes e veciños reúnense na casoupa familiar para despediren o fillo da costureira. Xa de madrugada, o avó saca o neno da casa e lévao a outro lugar próximo para que se reúna cun tío materno. Ambos teñen previsto viaxar ás Pontes nun carro de cabalos para posteriormente tomar rumbo ao Caribe.

$\mathrm{Na}$ medida en que iamos lendo esta historia, notabamos grande semellanza coa narrativa naturalista de Emilia Pardo Bazán, cando reproduce con pormenor a miseria material e moral dos personaxes, a perigosidade da orografía e a riqueza de sensacións visuais e gustativas, todas elas desagradábeis.

Esta lectura deixoume un sabor moi diferente, máis atractivo. Agora o centro de atención era o drama da mamá e do neno, a inmensa dor da separación. Por iso tiven paixón por ver como resultaba en galego aquela historia ambientada 
en Pesegueiro, en Curro de Eguas, no Porto Vello e no perigoso serrón, a onde levabamos as vacas sendo nenos un e outro. Naturalmente, estas circunstancias si que foron o suficientemente motivadoras para facer as lecturas adiadas durante tanto tempo e desta vez non houbo interrupción. Nin con Pedro Blanco, nin con Ramón Yendía, nin cos caios, nin coas traducións, nin coa produción xornalística que fun reunindo como pezas dun inmenso crebacabezas.

En función da experiencia propia, atrévome a formular a seguinte consideración: o estilo de Lino Novás, non só na literatura senón tamén no xornalismo, presenta un alto nivel de esixencia. Para aquelas persoas que carezan de hábito lector, o máis recomendábel é facer a aproximación desde os relatos (sexan os recollidos en Maneras de contar ou os das Otras maneras de contar) e a correspondencia (Laberinto de Fuego. Epistolario de Lino Novás Calvo) para chegar á narrativa longa e ao ensaio. O que está claro é que o esforzo merecerá a pena.

\section{AS DIFICULTADES PARA A DIVULGACIÓN}

Como consecuencia da enerxía propiciada pola lectura da obra, propuxémonos realizar algunha actividade divulgativa sobre a vida e obra de Lino Novás Calvo, primeiramente na comarca vertebrada pola Serra da Faladoira e despois no panorama cultural galego. Nesa altura entramos en contacto coa filla, a escritora Himilce Novas del Portal, con quen as novas tecnoloxías propiciaron tamén o encontro virtual.

Durante un período prolongado de tempo, mantivemos unha intensa correspondencia que nos forneceu de moitísima e moi valiosa información. Por ambas as partes coincidimos na necesidade de divulgar a obra literaria do escritor entre o público galego, e a escritora norteamericana manifestou o seu desexo de coñecer a terra de seu pai e mesmo de propiciar que a súa biblioteca, hemeroteca e documentación con ela relacionada puidesen estar á disposición do público en Galiza.

Mais as novas tecnoloxías que favoreceron a comunicación foron tamén as encargadas de a interromper temporalmente. Con todo, as portas estaban abertas e ese contacto serviu de ponte para facilitar a realización do audiovisual inspirado en «Un encuentro singular», coa produción de Manuel López, Andrés Santalla e X. Cheda, e coa colaboración de numerosos veciños como actores e actrices. 
A planificación destinada a conseguir o recoñecemento social para Lino Novás Calvo, ao tempo que se vincularía o seu nome ao da parroquia e comarca nativas, foi un absoluto fracaso; iso si, deixounos episodios dignos de seren levados á literatura. $\mathrm{O}$ único interlocutor interesado foi Cefucho e a súa influencia non abondou para mover as consciencias das persoas que tomaban as decisións.

Por todo isto, entenderán a miña infinita gratitude a Ramón Villares, a Emilio Grandío e a Emilia García polo intenso e eficaz traballo de xestión e investigación realizado polo Consello da Cultura Galega desde o mes de outubro de 2012, cando contactaron con Himilce Novas. A brillantez das xestións deu como resultado o que se quería: sentir presente a Lino aquí, na súa terra de orixe.

Coa luz desta documentación, a obra de Novás será interpretada desde a perspectiva da raíz, tal como se desprende dos criterios de presentación das xornadas. Por certo, vaian os parabéns para quen tivese a responsabilidade de redactar a introdución que aparece nos programas de convocatoria, por escribir algo tan acertado e tan lindo:

Lino Novás é un autor que ten un saibo cubano por aprendizaxe, pero inequivocamente galego por tradición familiar e mesmo cultural, aprendido na súa infancia ortegana mais tamén no intenso contacto que mantivo na capital cubana coa colonia inmigrante galega. El nunca negou as súas orixes, mais non foi dos emigrantes que esperaban ser recoñecidos nos seus lugares de procedencia. As feridas dunha difícil infancia e a súa condición de fillo de solteira marcaron a ferro as febras máis íntimas da súa personalidade. Cando veu a España en 1931, comezou o seu periplo de regreso pola súa aldea natal, pero nunca máis voltou, se ben mantivo relación epistolar coa súa familia.

Exiliado coa muller e a única filla nos Estados Unidos desde 1960, parecería terse perdida a relación coa súa terra natal. Pero a súa filla, Himilce Novas, atendeu unha voz interior que lle dicía que seu pai e a súa obra debían retornar a Galicia.

Case un século despois, niso estamos: no retorno a Galiza dun ser humano que aquí recibiu a primeira lección. 


\section{A PRIMEIRA LECCIÓN}

Esta lección tan marcante, por ser a primeira e por ser tan intensa, encerra unha etapa da vida do neno, a pesar da curta idade que este tiña. En referencia á experiencia migratoria, nalgunha ocasión o escritor manifestou que chegara ao Caribe procedente de «ningún país» e iso impactounos profundamente pola enorme carga emotiva que leva consigo.

Moitas veces temos pensado no alcance desa denominación «ningún país» e fixémolo con serenidade, desde o profundo sentimento de solidariedade con aquela mamá e con aquel neno. Nese momento reconsideramos aquela decepción de «Un encuentro singular». É obvio que Lino foi dun país, mais era aínda moi novo e descoñecía que se trataba dun país colonizado, completamente subordinado, que só interesaba como fonte de materias primas. Non sabía que ía dunha terra inmensamente rica en recursos, mais condenada á miseria por inxerencia externa e tamén por falta de reacción interior. O neno marchou dun país en que a burguesía tivo un erro monumental ao virarlles as costas, primeiro, ao proxecto político de Manuel Murguía e, despois, ao sindicalismo propugnado por Basilio Álvarez. Ese mesmo rapaz chegou a Cuba demasiado noviño como para saber que na Habana había centros asociativos en que se soñaba con transformar ese país ignoto tanto para o protagonista como para aqueles millares de compatriotas que con el compartían destino. Aínda que se supón que o seu tío xa levaría uns anos na Habana, é case seguro que non frecuentaría os círculos sociais en que se desenvolvera Cabanillas entre 1910 e 1915, e tampouco asistiría aos actos organizados nese mesmo decenio pola Unión Redencionista de Fontela Leal. Por iso interpreta así a realidade: por puro descoñecemento daquilo que non fose o seu desafortunado ambiente inmediato.

Por iso a Galiza de Lino Novás é plana, monolítica, de foto-fixa, fronte á perspectiva poliédrica do país que o acolleu e ao que el se incorporou: o seu país. Aquela si que é unha sociedade de contrastes. Así se percibe, por exemplo, en "Peor que un infierno», ese relato en que o narrador-testemuña é un xestor administrativo dunha empresa do sector madeireiro, situada na periferia da Habana; ese relato en que, cun orixinal xogo narrativo que combina o relato en terceira persoa coa perspectiva do narrador implicado nos feitos, o traballador da contabilidade móstranos a súa propia metamorfose. De ser un vagabundo que só 
procura nesa empresa o diñeiro suficiente para escapar aos Estado Unidos, pasa a levar unha vida absolutamente sedentaria. De exercitar a vinganza contra outros semellantes como manifestación de rancor pola violencia «de can sen dono», pasa a asumir pasivamente a dominación á que foi sometido pola esposa e o sogro.

Nese ambiente, ao lado da capital -rica pola arquitectura, capital administrativa e comercial, centro populoso- están os asentamentos periféricos onde se vive en constante perigo (inseguridade cidadá). Ese é o caso da familia de Mauro Rubio, un violento, "cetrino", capaz de matar unha persoa co mesmo sangue frío co que remata as reses no matadoiro. Nese ambiente de pobreza económica e miseria moral, entre seres que se meten por camiños sen saída, ten un final tráxico o tamén contable, Juan Toolo, inmigrante de orixe española, con apelido que semella galego desfigurado.

$\mathrm{Na}$ evocación de Galiza non hai contraste, porque o que xa levaba consigo o neno era unha ben completa dose de autoodio. Nas primeiras liñas do relato percibimos a causa á que se atribúe o atraso: a situación xeográfica do lugar. $\mathrm{O}$ rapaz ten a idea de nacer no «cu do mundo» e asimila que para progresar é condición fundamental saír de tal inferno ( En Galiza non se pide nada; emígrase» -dixo unha voz que falou por todos nós). A saída da nosa terra é unha liberación; por fin pode escapar deste lugar de clima tan ruín. Iso despréndese das primeiras palabras («chovera sen cesar todo o día, toda a semana, todo o mes. Chovía a todas as horas»), evocadoras dunha especie de ser superior que nos quixese torturar a base de enchentes que atacan as persoas, os animais, as colleitas e as vivendas.

Á vista deste contraste, onde se estaba no inferno... e onde se estaba "peor que no inferno»? Parece como se o escritor nacese condenado a peregrinar de inferno en inferno e que despois se especializase en contarnos as vivencias de cada un deles. Evidentemente, o inferno de «Aquella noche salieron los muertos» non ten unha temperatura nada inferior ao que tiña o de Pesegueiro.

\section{A REFLEXIÓN SOBRE A IDENTIDADE}

Se «La primeira lección» é tamén a primeira lección de moitas e moitos de nós, «Un encuentro singular» non é menos lección nin menos nosa, aínda que non sexa a primeira. Mais esas leccións son as que determinan intensamente as nosas 
vidas e as que van marcando cada unha das etapas. Pasou con Lino en 1910 e en 1931, e pasou coa nosa xeración sesenta anos máis tarde. Cantos anos tiñamos cando soubemos que existía outra Galiza diferente á nosa? Cantos anos tiñamos cando descubrimos que Rosalía de Castro xa falara por nós ou que Neira Vilas lle dera a palabra a Balbino e que o tal Balbino podía ser irmán noso? Incluso máis: cal é a porcentaxe da poboación que asimila hoxe como algo propio os discursos de Rosalía ou de Balbino?

Quen non medrou escoitando ao fondo as voces de persoas como o vello Verdeal? Quen non sentiu os comentarios do indiano que retornou transculturado na roupa e na fala e que lles falaba así ás veciñas que choraban na despedida do neno?:

Llorando, llorando. Todo en esta tierra es lagrimeo y pelambre. Llorando porque se le va el hijo, cuando debería cantar. Cada uno que se va debería ser una fiesta en este lugar. Yo, rey, los mandaba salir a todos, hasta que no quedaran más que los sordos y los reumáticos. Mandaba acá una compañía de fusileros y me los llevaba a todos por delante.

Eu crieime nese ambiente e tamén quixen escapar da miseria. Eu tamén sentín moita vergoña e tamén acabei cegado polo mundo de cores que descubría a través dos xornais e da radio. Tamén sentín moita vergoña da nosa fala, porque pensei que era unha marca da nosa inferioridade e porque a vin como obstáculo para aprender outras. Eu tamén sentín no Barqueiro e en Ortigueira a presión ofensiva como Lino a sentiu na Habana por parte doutros nenos. Mais en ambos a esencia mantívose viva e co tempo vivimos a nosa propia metamorfose. Por iso, foi moi emotivo constatar que a nena Himilce - nacida e criada a millares de quilómetros de onde naceu seu pai- escoitou no berce e nos brazos algunhas cantigas de agarimo que Lino recibira da boca da costureira. Por iso, para Himilce Novas o nome de Rosalía non é alleo, e iso contribúe a que se sinta algo galega sen estar nunca fisicamente na nosa terra. 


\section{RECTIFICAR A HISTORIA}

Felizmente, na actualidade, a nosa terra en conxunto e tamén a nosa comarca están «a anos luz» das vivencias que recolle Lino Novás nos seus tres (ou incluso catro) relatos de temática galega. De todos os xeitos, debemos comprender que a que el conta foi a nosa historia, que aquelas son as vivencias de millares de homes e mulleres que durante o século Xx tiveron que buscar o pan noutras latitudes. Ese panorama de miseria existiu: as casoupas; as vacas fracas e aterecidas que criaban vermes entre o coiro e a carne; as persoas de negro, mal comidas, mal vestidas e mal calzadas; as mulleres de ventres prominentes, típicos da alimentación insuficiente; os nenos descalzos, con síntomas de raquitismo; a alimentación a base de pan negro, caldo de verzas, zonchos e papas con pouco leite; a falta de leña para o lume... Todo iso e tamén a falta de infraestruturas mínimas (escolas, sanidade, vías de comunicación), a falta da propiedade da terra e a ausencia de institucións que gobernasen esta nosa terra co seu desenvolvemento como prioridade. Mais isto último non o pode entender un rapaciño, e non é nada estraño que non o entenda porque moita xente non o chega a entender nunca.

Termino co seguinte: agora temos ao noso alcance a documentación. É o momento de debruzarse nela e de estudala. É o momento de estudar a historia para rectificar o que sexa necesario, por exemplo, na educación (na familiar e na escolar). É o momento de seguir o exemplo de Lino Novás, que tamén rectificou o erro de 1931, talvez porque recibise comentarios críticos ao publicar «Un encuentro singular» en La Gaceta Literaria ou talvez como resultado do seu contacto con Rafael Dieste entre 1940 e 1941, durante o proceso de edición de La luna nona, obra que apareceu en Bos Aires baixo o carimbo de Losada, empresa para a que traballaba o rianxeiro (único referente da literatura galega citado por Novás). Sexa pola razón que for, o caso é que a experiencia impeleuno a rectificar e rectificou. Non só o constatamos a través das palabras da súa filla, senón que xa o intuïamos ao ler en Maneras de contar a presentación que antecede ao relato antes citado e que di así:

Un profesor americano, Raymon Sousa, encontró este cuento, por mi olvidado, en una colección de La Gaceta Literaria. [...] El tema me lo había dado, años antes, en La Habana, un emigrante español. No se trate de hallar, pues, ningún elemento autobiográfico en esta historia. 
Non dubidamos de que o tema llo dese na Habana un emigrante español. Seguro que había moitos que llo podían dar, mesmo tantos que o último enunciado sería moito máis exacto se tivese unha palabra máis: o adxectivo "exclusivo». Porque certamente «elemento autobiográfico» que sexa exclusivo non hai ningún, porque esta é infelizmente a historia dun comportamento colectivo que cómpre corrixir.

No proceso de revitalización da cultura galega temos moito que aprender a partir da reflexión sobre a vida e a obra de Lino Novás Calvo, a quen estamos estudando desde unha óptica galega. Mais o seu recoñecemento como galego non o fai menos cubano. As teses de Ana Chouciño ou de Luís G. Tosar non ensombrecen as de Raymon Sousa, Cira Romero ou Carlos Espinosa. Moi ao contrario: a propia realización das Xornadas é a constatación de que os seus respectivos esforzos serviron e serven.

Acabamos facendo xustiza: co agradecemento infinito para Himilce Novas, pola súa xenerosidade; tamén moi especialmente para Jesús Pardo Novás, Cefucho e Ernesto Vale Carballés, ambos grañeses; e para Antonio Rivera Losada, Vicente Peña Saavedra e David Fojo Salgueiro, polas voltas e reviravoltas que deron para que fose posíbel o retorno de Lino Novás á súa terra de orixe. 